\title{
A ESTÉTICA MEMORIALÍSTICA ENQUANTO FONTE NA OBRA A COR DA TERNURA (2018), DE GENI GUIMARÃES: A LITERATURA COMO INSTRUMENTO DE RESSIGNIFICAÇÃO HISTÓRICA DAS PERSONAGENS NEGRAS
}

\author{
MEMORIALISTIC AESTHETICS AS A SOURCE IN THE WORK $A$ COR DA \\ TERNURA (2018) BY GENI GUIMARÃES: \\ LITERATURE AS A WAY FOR HISTORICAL REMEANINGS OF BLACK \\ CHARACTERS
}

\author{
Marcio da Silva Oliveira ${ }^{1}$ \\ Matilde Costa Fernandes de Souza ${ }^{2}$ \\ Michele de Fátima Sant'Ana ${ }^{3}$
}

\begin{abstract}
Resumo: Refletimos aqui sobre a importância da escrita feminina enquanto criadora de protagonistas femininas e negras na literatura infantojuvenil e sua representatividade. Acreditamos que na obra de Geni Guimarães (2018), por meio da estética memorialística enquanto fonte de análise crítica, sociológica e de resistência identitária - encontramos um discurso de valorização da imagem do negro e de respeito à diversidade, à cultura, à história e às tradições desse sujeito e do povo a que representa. Isso leva à reflexão e à formação de um leitor literário consciente quando a ela se tem acesso, contribuindo para a ressignificação do passado e de sua própria vida.
\end{abstract}

Palavras-Chave: estética memorialística; escrita feminina; crítica feminista; raça e identidade; literatura infantojuvenil.

\begin{abstract}
We reflect here about the importance of feminine writing as a creator of female and black protagonists in children's literature and their representativeness. We believe that in the work of Geni Guimarães - through memorialistic aesthetics as a source of sociological critical analysis and identity resistance - we find a discourse that values the image of black people and respect concerning the diversity, culture, History and traditions of the people which it represents. That leads to reflections and to the formation of a conscious literary reader when he has access to it, contributing to the remeaning of the past and his own life.
\end{abstract}

\footnotetext{
${ }^{1}$ Doutor em Letras pela Universidade Estadual de Maringá-UEM- MaringálPR, na área de concentração Estudos Literários: Literatura e Historicidade. Bolsista Capes\Fundação Araucária de Pós-doutorado em Literatura Comparada na Unioeste-Cascavel-PR, sob supervisão do Prof. Dr. Gilmei Francisco Fleck. Integrante do grupo de pesquisa "Ressignificações do passado na América Latina: leitura, escrita e tradução de gêneros híbridos de história e ficção - vias para a descolonização", liderado pelo Prof. Dr. Gilmei Francisco Fleck. E-mail: prof.marcioliveira2015@gmail.com

${ }^{2}$ Mestre em Letras pelo Profletras/Unioeste, Cascavel-PR, docente da Escola Municipal José Henrique Teixeira, Cascavel-PR. Integrante do grupo de pesquisa "Ressignificações do passado na América Latina: leitura, escrita e tradução de gêneros híbridos de história e ficção - vias para a descolonização", liderado pelo Prof. Dr. Gilmei Francisco Fleck. E-mail: mcfernandes76@gmail.com

${ }^{3}$ Mestre em Letras pelo Profletras-Unioeste/Cascavel-PR, Doutoranda no Programa de Pós-Graduação em Letras da Unioeste/Cascavel, PR. Docente da Escola Municipal Levino Jorge Weidmann-Santa Tereza do OestePR. Integrante do grupo de pesquisa "Ressignificações do passado na América Latina: leitura, escrita e tradução de gêneros híbridos de história e ficção - vias para a descolonização", liderado pelo Prof. Dr. Gilmei Francisco Fleck. E-mail: michelefsantana@gmail.com
} 
Keywords: Memorialistic Aesthetics; Feminine Writing; Feminist Criticism; Race and Identity; Children's Literature.

\section{Introdução}

A leitura, sobretudo a do texto literário, é fundamental na infância e na adolescência, pois, nessas fases, o sujeito está em processo de formação e a escola, ambiente considerado ideal à prática e incentivo da leitura da literatura, deve estar ciente do papel que precisa desempenhar para concretizar o processo de formação de leitores conscientes, reflexivos e críticos. Nessa perspectiva, o presente trabalho busca refletir sobre a possibilidade de compreender, de maneira inovadora, a ressignificação da história para rompermos com os estereótipos das personagens negras da literatura infantojuvenil criadas pela escrita feminina e negra de Geni Guimarães. Esse nosso intento se concretiza por meio da leitura e análise da obra A Cor da Ternura (2018) e das ações e reflexões de sua protagonista em todas as fases de sua vida. A personagem de Guimarães convive e tem sua negritude confrontada desde a infância até a idade adulta, sempre em busca de seus ideais e na construção de sua identidade feminina e negra, circundada por uma sociedade patriarcal, machista, branca e excludente.

Dessa maneira, para refletirmos sobre a importância da escrita feminina e do protagonismo negro na literatura infantojuvenil, procuramos utilizar, como apoio e referencial teórico, a estética dos gêneros memorialísticos enquanto fonte de análise crítica e sociológica, a fim de buscarmos meios que proporcionem a reflexão e, também, um novo olhar para as histórias que nos foram contadas. Tais ações são válidas para que o leitor tenha a possibilidade de entrar em contato com outra versão dos fatos, por meio de uma voz antes apagada, calada, sufocada, desconhecida e marginalizada (a voz da mulher negra, escrava, analfabeta e tida, por muito tempo, como objeto) para, somente assim, ter condições de ressignificar tanto as próprias histórias das mulheres como os fatos do passado opressor.

Acreditamos que, ao analisar a desconstrução de estereótipos acerca do negro na obra de Geni Guimarães - evidenciando a presença de um estilo de discurso inovador, por meio da voz feminina que narra, que escreve e que valoriza as características étnico-raciais do negro seja possível contribuirmos, por meio de reflexões e contrapontos, com a ressignificação da personagem negra no âmbito literário, o que favorece uma auto aceitação identitária, reconhecimento e valorização de nossa cultura desde a infância, fase para a qual a obra está destinada em primeira instância.

Buscamos, também, verificar como a representação das personagens negras e a imagem que emerge dos gêneros memorialísticos na tessitura dos textos ocorre. Desse modo, 
teremos a possibilidade de identificar se há pontos de desconstrução do estereótipo negativo, historicamente criado em torno do negro e seu apagamento, nessa produção ou a permanência dos mesmos, tomando como objeto a obra por nós proposta: A Cor da Ternura (2018), de Geni Guimarães.

$\mathrm{Na}$ perspectiva de alcançar os objetivos propostos, buscamos sustentar nossos propósitos nos pressupostos teórico-metodológicos da pesquisa bibliográfica e na interpretação da narrativa escolhida como corpus, à luz da escrita crítica e feminina e da teoria literária que trata da estética contida nos gêneros memorialísticos, como também nos elementos constitutivos da narrativa: enredo, espaço, narrador e personagem, com um olhar voltado para a literatura infantojuvenil.

Desta forma, para o campo da crítica literária, realizamos a pesquisa sobre as personagens negras retratadas na obra A Cor da Ternura (2018), de Geni Guimarães, de modo a apresentar as principais caracterizações atribuídas a elas na tessitura dos textos. Para refletir acerca da questão étnico-racial na obra literária, levamos em conta as considerações de relevantes estudiosos das Ciências Humanas e Sociais, para visualizarmos os fios do "racismo à brasileira" e do "mito da democracia racial", os quais vêm corroborando para a dissimulação e disseminação do preconceito e da ideologia do branqueamento no país, haja vista a influência desses ideários em nosso cotidiano.

Desse modo, acreditamos que a literatura infantojuvenil é uma importante produção artística e deve ser ainda mais estudada e valorizada no contexto escolar, pois, é por meio das obras escritas por autoras negras, e constituída por personagens negras, que surgem as possibilidades de (re)leituras, análise das relações raciais, (re)afirmação identitária e ressignificações socioculturais, de forma a desconstruir a conotação negativa a elas atribuída ao longo do tempo.

Na tentativa de constatar se houve inovação na elaboração das personagens negras ao longo do tempo, e por meio das obras, buscamos atentar-nos à expressão de determinados preconceitos e estereótipos na tessitura do relato, com base nas pesquisas realizadas por estudiosos de obras literárias. Afinal, conforme Silva (2009), “o [...] termo negro é carregado de conceitos e preconceitos. É carregado também de lembranças, de lutas na construção da identidade. O termo negro nos remete a sujeitos sociais históricos, a diversidades raciais e culturais."

A análise interpretativa da obra escolhida como corpus, enfocando as personagens suas características e atributos - pautar-se-á à luz da teoria referente à literatura infantojuvenil 
em nosso país, com vistas a responder o questionamento: na narrativa infantojuvenil de Geni Guimarães, as personagens negras são caracterizadas de maneira inovadora? Há o rompimento com estereótipos negativos que inferiorizam a sua imagem, silenciam sua voz e as tornam invisíveis no discurso historiográfico hegemônico?

Partimos da hipótese de que, na produção literária da referida autora, encontramos um discurso de valorização da imagem do negro e de respeito à diversidade, à cultura, à história e às tradições desse sujeito - e do povo a que representa - , fato que proporciona ao leitor questionamentos reflexivos e contribui, dessa forma, para o alargamento de seus horizontes, enriquecimento e transformação de sua vida, instigando-o à formação de uma consciência crítica.

\section{A Literatura Infantojuvenil e a ressignificação histórica: algumas reflexões}

A visível e crescente preocupação com a promoção e o incentivo da leitura, em especial a da leitura de obras literárias que vise à formação de leitores nas escolas, não é uma tendência da atualidade. Estudos nesse sentido revelam que, a partir da década de 1970, surgem e se intensificam programas que contemplam a leitura dessa modalidade de texto.

Embora haja vários estudos e pesquisas sobre leitura, a literatura infantojuvenil e a importância do letramento literário, este tema está longe de ser esgotado. Há ainda importantes aspectos e realidades muito distintas que podem ser discutidos e colocados em foco. Isso porque a real significação do ato de ler deve estar além da decodificação de signos linguísticos, pois, para que tal prática se constitua como leitura crítica e reflexiva e, consequentemente, produza, no leitor, condições de transformação da realidade vivida, a mesma deve passar pelo crivo não só da decodificação, mas também da re-codificacação, da interpretação, da ressignificação e, principalmente, da inferenciação e do dialogismo construído pelo leitor com o autor, com a obra e com as diversas vozes nela encontradas. Obras mistas de história e literatura são, nesse contexto, leituras preciosas que, além de expandir horizontes, levam o sujeito leitor à prática da confrontação de discursos, estratégia que é fundamental à formação de um leitor consciente.

A leitura é fundamental e sua prática é extremamente relevante. Abordá-la ainda é um ato complexo, pois, de acordo com Magnani (2001, p. 42), deve ser compreendida como "um fenômeno social que envolve as condições de emergência e utilização de determinados escritos, em determinada época: é pensá-la do ponto de vista de seu funcionamento sóciohistórico [...]", que exige conhecimento tanto de teorias quanto de fatos históricos e sociais. 
Dessa maneira, os textos híbridos de história e ficção, introduzidos na literatura infantojuvenil, cumprem essa relevante tarefa de proporcionar um espaço representacional, no qual o aprendiz pode, e deve, enfrentar-se com discursos opostos em relação à escrita sobre o passado desde o início de sua formação como leitor.

Valorizar a leitura é imprescindível à sociedade que busca renovação, humanização e cognição. Assim, a leitura, especialmente a do texto literário, é fundamental para o educando, pois, este se encontra em processo de formação, e a escola, ambiente tido como ideal e fomentador para a sua prática, necessita ter ciência do papel que deve desempenhar para concretizar o processo de formação de leitores conscientes.

Dessa maneira, o desenvolvimento da capacidade leitora em um indivíduo pode desobstruir "o processo de construção de sua cidadania" (YUNES, 2002, p. 54) se possibilitar que o mesmo participe das relações sociais de forma crítica, podendo ser capaz de expressar suas opiniões, de refletir e tomar decisões que sejam coerentes à sua realidade, haja vista que, em nossa sociedade atual, o que está em jogo é a sobrevivência do ser humano em suas mais variadas formas e relações de sociabilidade.

O desenvolvimento de práticas de leitura vai muito além da compreensão literal e aparente das palavras impressas. É necessário interpretá-las, relacioná-las com outros textos, enunciados e discursos, de forma a replicar, ressignificar, conseguir identificar as possíveis posições e ideologias que constituem os sentidos das palavras. Segundo Silva: - 5 - A literatura pode oferecer informações características de uma determinada sociedade, considerando que tais sinais são representações, muitas vezes não diretas, que são apresentadas mediante o ponto de vista, ou seja, o pensamento, os valores e as crenças do autor do texto literário (2008, p. 1).

Ao pensarmos a literatura como um campo ideológico, em que são expressadas as formas de percepção do mundo, entendendo-a como um produto social que emerge em um determinado contexto histórico, o presente artigo busca refletir sobre o reconhecimento da identidade negra, desconstrução de estereótipos, a construção das personagens negras na literatura e como uma obra literária pode influenciar na aceitação e ressignificação desta identidade.

Segundo Arboleya (2009), a literatura infantojuvenil apresenta, em sua forma primária, como personagem principal o branco, idealizando o seu estereótipo de beleza e poder e verifica-se nas obras que as personagens não brancas são colocadas majoritariamente em segundo plano, submissas, inferiores e sem voz ativa. Uma expressiva parte das obras 
infantojuvenis apresenta a "[...] construção de estereótipos em relação à representatividade social e cultural e à construção da identidade étnica.” (ARBOLEYA, 2009, p. 4). Ainda tratando dos estereótipos, Souza (2001) aponta o livro didático e o currículo escolar como fontes potenciais que podem alimentar o preconceito racial no ambiente escolar.

De acordo com Hall (2011), há três concepções de identidade: do sujeito do Iluminismo, a do sujeito sociológico e a do sujeito pós-moderno. a) O sujeito do iluminismo é caracterizado pela centralidade, pela unificação do próprio eu. É uma concepção de identidade fixa, que defende o indivíduo como um ser individual. b) a do sujeito sociológico, aquele nas quais as pessoas refletem a crescente complexidade do mundo moderno, ou seja, a identidade é formada na interação do eu e a sociedade, ocupando o espaço entre o mundo pessoal e o mundo público. c) e a concepção do sujeito pós-moderno, no qual surge o conceito de um sujeito que não tem uma identidade fixa, única ou permanente. Em vez disso, a identidade modifica-se constantemente.

Diante de tais concepções, Hall (2011, p. 13) afirma que "[...] o sujeito assume identidade diferente em diferentes momentos. [...] A identidade plenamente unificada, completa, segura e coerente é uma fantasia.” Assim, pode-se constatar que a construção da identidade do indivíduo está relacionada com o processo entre o eu e o mundo no qual o sujeito pode comportar-se de maneira diferente dependendo das possibilidades que estão ao seu alcance, ou seja, o sujeito não permanece idêntico, mas, em vez disso, sofre continuamente influências do meio em que vive e das pessoas que compõem este meio. Hall coloca que as identidades

não são nunca unificadas; que elas são na modernidade tardia, cada vez mais fragmentadas e fraturadas; que elas não são, nunca, singulares, mas multiplamente construídas ao longo de discursos, práticas e posições que podem se cruzar ou ser antagônicos. As identidades estão sujeitas a uma historicização radical, estando constantemente em processo de mudança e transformação (2000, p.108).

Em seus estudos, Woodward (2009, p. 11) assevera que “[...] uma das formas pelas quais as identidades estabelecem suas reivindicações é por meio do apelo a antecedentes históricos", nos quais o sujeito resgata a sua identidade no passado. Tal concepção de construção de identidade refere-se a algo ou alguém que já não existe mais ou foi fonte de referência em um determinado momento e nos impulsiona a repensar que o negro pode apresentar identidades díspares em diferentes momentos históricos, e que, quando assume a sua identidade, torna-se um sujeito empoderado, independente e livre, proporcionando a construção de pensamento e formas de ser que resulta em novos horizontes e o leva à 
conquista de novos espaços. Esta identificação é fundamental para o exercício da cidadania em diferentes posições, ou seja, precisa-se ter clareza que assumir uma ou outra posição é fazer escolhas que podem ser avaliadas e justificadas por quem as assume.

Ao considerarmos que a construção de identidade se dá por meio do intercâmbio entre o individual e o coletivo, mediado por um conjunto de crenças, códigos e valores instaurados historicamente e ao analisarmos A Cor da Ternura (2018), de Geni Guimarães, é possível verificar em alguns fragmentos a discriminação racial visivelmente presente na vida das personagens negras retratadas. Essa problemática é vivenciada da mesma forma pela personagem principal da história, que assim como a autora, também se chama Geni. Guimarães aborda em suas obras questões referentes à temática negra, com o intuito de buscar a valorização da cultura afrodescendente.

A Cor da Ternura (2018) retrata um conflito sofrido por uma criança negra, pobre e que enfrenta o preconceito de outras crianças no lugar onde vive e na escola. Porém, ao longo do enredo, a protagonista constrói sua identidade pautada nas experiências vividas no decorrer de sua infância até a vida adulta. A leitura da obra nos permite estabelecer vários vínculos entre o passado histórico, vivenciado pela comunidade negra do Brasil, e a realidade vivida na contemporaneidade pelos descendentes afro-brasileiros. Tais temáticas têm chamado a atenção de uma série de escritoras brasileiras ${ }^{4}$ que buscam pela arte literária expressar novas perspectivas sobre o passado de submissão ao qual esse contingente esteve sujeito ao longo dos séculos de história brasileira.

Diante do contexto acima exposto, e segundo Zolin (2003), desde a década de 1960, com o desenvolvimento do pensamento feminista, a mulher vem se tornando objeto de estudo em diversas áreas do conhecimento e, também, no âmbito da Literatura e da Crítica Literária. Essa presença ultrapassa o pontual e o eufórico para se conjugar a todo um processo histórico literário e, mais importante que os debates gerados, são os efeitos provocados por ele, pois, essa vertente da crítica literária tem assumido o papel de questionadora das práticas patriarcais acadêmicas.

[...] a constatação de que a experiência da mulher como leitora e escritora é diferente da masculina implicou significativas mudanças no campo intelectual, marcadas pela quebra de paradigmas e pela descoberta de novos horizontes de expectativas (ZOLIN, 2003, p. 181).

\footnotetext{
${ }^{4}$ Entre elas podemos mencionar Ana Miranda, Maria José Silveira, Heloisa Maranhão, Conceição Evaristo, entre outras.
} 
A propagação de concepções pautadas, na ideologia patriarcal, estabeleceu que as mulheres fossem inferiores aos homens, o que o leva a posição de submissão, enquanto aqueles se constituíam como dominadores.

Em sua obra, Guimarães (2018), apresenta as dificuldades enfrentadas por pessoas negras, sobre o racismo e o preconceito sofrido, mas, também, uma nova visão da personagem negra, ou seja, traça uma nova imagem cerceada de elementos positivos como o amor da mãe pela filha, o respeito, como contatamos na citação abaixo:

Ela era linda. Nunca me cansei de olhá-la. O dia todo arrastava os chinelos pela casa. Ia e vinha [...] Quando me pegava no flagra, bebendo seus gestos, esboçava um riso calmo, curto [...] Revivia o riso dela mil vezes e à noite deitava-me mais cedo para pensar no doce cheiro de terra e mãe (GUIMARÃES, 2018, p. 13).

Essa forma positiva de retratar a personagem negra da qual Guimarães (2018) se utiliza, é muito diferente do que normalmente constatamos em literaturas relacionadas à essa temática. Pois, na maioria das obras encontramos o negro retratado como um ser inferior e submisso aos brancos e detentores do poder. Podemos verificar em alguns fragmentos da obra as dúvidas, as incertezas enfrentadas pela protagonista: "Saudades dos meus detalhes perdidos. Do meu colo, da minha comida servida na boca. [...]" (GUIMARÃES, 2018, p. 24). A construção da identidade, conforme Woodward (2009), também pode estar relacionada com o passado, e, nesse excerto Guimarães, demonstra a saudade de algo que, para ela, era a forma natural da sua vida. Essas mudanças fazem com que a protagonista estabeleça uma situação de conflito consigo mesma em relação à visão de outras pessoas sobre ela.

Na obra A Cor da Ternura (2018), é retratado as experiências da protagonista-menina que ao chegar à escola, vai descobrindo a sua cor nos seus primeiros anos escolares, e com esta todo o racismo, o preconceito e a posição social que existem na sociedade: “[...] - Não tenho nada com isso, mas vocês de cor são feitos de ferro. O lugar de vocês é dar duro na lavoura. Além de tudo, estudar filho é besteira. [...]" (GUIMARÃES, 2018, p. 73). A menina começa a desperta para a problemática da exclusão racial.

Dessa maneira, a autora aborda, pelas vozes das personagens, traço de um passado histórico de colonização e escravidão. Entretanto, a autora desenvolve, também, a temática da resistência, imposição enquanto mulher negra e munida de voz e a construção de identidade, gerando reflexões sobre questões étnicas ao longo do relato.

Pollak (1992, p. 05) reforça que “[...] memória e identidade podem perfeitamente ser negociadas, e não são fenômenos que devam ser compreendidos como essências de uma 
pessoa ou de um grupo". Memória e identidade são fatores contínuos e correspondentes a uma pessoa ou a um grupo, dessa forma podem ser alterados e reestruturados. Desta forma, a interação com o meio social é significativa, na construção e perpetuação da memória e identidade de um povo.

Woodward (2009), enfatiza que a identidade está vinculada às relações de poder e saber, nas quais, muitas vezes, a identidade étnica não é entendida como essencial, e a criança passa por diversas mudanças de personalidade, pois, vai formando seus conceitos e concepções positivas e negativas no âmbito social em que vive. Daí a importância que atribuímos à leitura de textos híbridos de história e ficção no espaço escolar. Textos dessa natureza geram consciência e auxiliam na formação de leitores aptos a realizar a confrontação de ideias e discursos disseminados na sociedade e representados na arte literária.

A instituição escolar é um dos espaços sociais onde a criança fica por um longo período e é um dos lugares fundamentais para a construção da identidade do indivíduo desde a infância. Sabemos que o silêncio da escola contribui para que o racismo e o preconceito sejam vistos pelas crianças, muitas vezes de modo distorcido. A falta de posicionamento crítico dentro da instituição, muita vezes, faz com que as crianças brancas se sintam superiores às negras, e estas, por sua vez, sintam-se inferiores, isso reflete os processos sociais da sociedade em que o indivíduo está inserido. Por isso, que uma das formas de combater o racismo e construir uma representação positiva sobre o afro-brasileiro é a desnaturalização das desigualdades raciais.

Gomes (2004) assevera que é de responsabilidade do professor, tal tarefa. E,

Talvez, um primeiro passo a ser dado pelas educadoras e pelos educadores que aceitam o desafio de pensar os vínculos entre educação e identidade negra seja reconhecer que qualquer intervenção pedagógica a ser feita não pode desconsiderar que, no Brasil, vivemos sob o mito da democracia racial e padecemos de um racismo ambíguo. A partir daí, é preciso compreender que uma das características de qualquer racismo é sustentar a dominação de determinado grupo étnico/racial em detrimento da expressão da identidade de outros. É no cerne dessa problemática que estamos inseridos, o que significa estarmos em uma zona de tensão. (GOMES, 2004, p.6)

Diante disso, notamos a urgência de trabalharmos em sala o aspecto da identidade afro-brasileira, visando seu processo de empoderamento. Entendemos que isso fortaleça a autoconfiança desse grupo marginalizado em questão. O caminho escolhido foi o da literatura por acreditarmos que seja possível nos posicionamos a favor de uma literatura que seja um espaço plural, acolhedor de várias leituras e análises, local privilegiado de produção e 
reprodução simbólica de sentidos e, desse modo, fonte que pode colaborar para a enunciação ou para a invisibilidade, para a valorização ou subalternidade das identidades.

Consciente dessa realidade, Guimarães (2018), traz ao campo da representação literária tais enfrentamentos e a protagonista muda a sua forma de olhar o negro, devido às condições sociais, que têm como referentes a visão da professora e dos demais colegas brancos, como podemos ler no segmento destacado abaixo:

\footnotetext{
Quantas vezes deviam ter rido de mim, depois das minhas tontices, em inventar cantigas de roda... Vinha mesmo era de uma raça medrosa, sem histórias de heroísmo. Morriam feito cães... Justo era mesmo homenagear Caxias, Tiradentes e todos os Dom Pedro da História. Lógico. Eles lutavam, defendiam-se e ao seu país. Os idiotas dos negros, nada (GUIMARÃES, 2018, p. 67).
}

Outro aspecto enfatizado pela a autora é o preconceito racial, a forma como ele ocorre nas passagens em que a personagem está juntamente com as outras crianças: “[...] Boneca de piche, cabelo de bom-bril eram ofensas de rotina" (GUIMARÃES, 2018, p. 46). Isso é pontuado também no relato quando a mãe aconselha a filha a agir com paciência como se nada houvesse escutado: "E se, no caminho, o Flávio me xingar de negrinha? - não quero saber de encrenca, pelo amor de Deus! Você pega e faz de conta que não escutou nada" (GUIMARÃES, 2018, p. 47); e como a menina se sente diante de tudo o que houve: "Eu era a única pessoa da classe representando uma raça digna de compaixão, desprezo!" (GUIMARÃES, 2018, p. 65). São as vagas lembranças de um passado de escravidão que geram tais imagens na literatura.

Incentivar um processo de leitura comparada - da história e das imagens ficcionais produzidas em A cor da ternura (2018) - é, seguramente, uma ação descolonizadora capaz de produzir reflexões mesmo em estudantes em formação inicial.

No decorrer da narrativa, fica mais evidente a diferença entre a protagonista e a outras crianças no que se refere à cor. Tudo isso ocorre devido aos acontecimentos de discriminação racial, que ela vivencia quando começa a ir à escola e, também, nos conselhos dados pela mãe, para proteger a filha de humilhações ou situações constrangedoras, conforme podemos constatar no fragmento:

Pelo amor de Deus, não vai esquecer o nariz escorrendo. Lava o olho antes de sair. - Se a gente for de qualquer jeito, a professora faz o quê? - perguntei. - Põe de castigo em cima de dois grãos de milho - respondeu-me ela. - Mas a Janete do seu Cardoso vai de ramela no olho e até muco no nariz e... - Mas a Janete é branca respondeu minha mãe, antes que eu completasse a frase (GUIMARÃES, 2018, p. 48). 
Podemos verificar nessa citação que, a protagonista nota que essa diferença remete à sua cor, à sua pele e à raça. Conforme Silva (2009), a identidade e a diferença simplesmente existem e são concebidas como algo que remete a si próprio e, ainda, que a diferença é marcada por representações simbólicas. São essas marcas que desenvolvem significados às relações pessoais.

Segundo Hall (2011), o sujeito, ao longo de sua trajetória, fragmenta-se e pode comporse não de uma única, mas de várias identidades, algumas vezes contraditórias ou não resolvidas. Isso pode ser observado em A Cor da Ternura (2018), no capítulo intitulado "Metamorfose, uma passagem bastante crítica e dolorosa é quando em meio aos sofrimentos enfrentados em função de sua cor, Geni passa por um processo de autonegação, apresentando, mais uma vez, dúvidas e incertezas sobre si. Uma identidade não resolvida, como vemos no trecho abaixo:

\begin{abstract}
Assim que terminou a arrumação, ela voltou para casa, e eu juntei o pó restante e com ele esfreguei a barriga da perna. Esfreguei, esfreguei e vi que diante de tanta dor era impossível tirar todo o negro da pele. Daí, então, passei o dedo sobre o sangue vermelho, grosso, quente e com ele comecei a escrever pornografias no muro do tanque d'água (GUIMARÃES, 2018, p. 69).
\end{abstract}

Segundo Woodward (2009), os termos identidade e subjetividade são utilizados de forma correlativa, ou seja, a subjetividade sugere a compreensão que se tem sobre o próprio eu, envolvendo sentimentos e pensamentos mais pessoais. Já a identidade é processo formado em um determinado contexto social, vivenciado por nós, no qual a linguagem e a cultura são significativas. No excerto acima, constata-se uma baixa estima da personagem protagonista, uma falta de confiança em si, sentimentos negativos referentes à aceitação da pigmentação da sua pele, e que, segundo Woodward (2009), são os sentimentos envolvidos no processo de produção da identidade. É nesta fase de consciência de si e da sua cor que a personagem começa a sua construção identitária.

$\mathrm{Na}$ obra, o pai aparece como o incentivador da protagonista, pois, quando percebe que ele desejava estudar os filhos, "[...] se apenas a gente pudesse estudar os filhos..." (GUIMARÃES, 1998, p. 72), Geni começa a definir a sua identidade, buscando realizar o desejo do pai, vencendo o preconceito da sociedade. Está presente também no livro a figura do pai como alguém trabalhador, atencioso e preocupado com a família, “[...] colocou o machado no ombro e saiu assobiando" (GUIMARÃES, 2018, p. 26), ou seja, a autora faz com que a identidade negra seja vista de forma a positiva, valorizando-se a cultura negra e destacando o respeito às raízes ancestrais, como podemos visualizar, por exemplo, no fragmento abaixo: 
Meu pai chegou do trabalho na lavoura, tirou do ombro o bornal com a garrafa de café vazia e sentou-se num degrau da escada da porta da cozinha [...]. Trouxe-lhe, e, ao desembrulhar o fumo, ele deu com a cara do Pelé sorrindo no jornal [...]. Este sim teve sorte. Lê aí pra mim, filha [...] Peguei o jornal e comecei a ler o comentário, que contava suas façanhas esportivas e dava algumas informações sobre a vida fantástica do jogador. [...] olhava no rosto do meu pai e ele soltava ameaços de risos (GUIMARÃES, 2018, p. 70).

A obra A Cor da Ternura (2018), retrata uma família unida, que apoia a formação da identidade da personagem, pois, foi com esse apoio que a personagem Geni torna-se mulher e, com muito esforço, vai à luta, como podemos verificar no fragmento a seguir, no qual fica visível a autoestima e a aceitação da personagem, num constante processo de vir a ser.

Mulher, terminando o ginásio. Mulher, cursando o normal, a caminho do professorado, cumprindo o prometido. Mulher, se fazendo, sob imposições, buscando forças para ser forte. Mulher, cuidando da fala, misturando palavras, pronúncias suburbanas aos mil modos de sinônimos rolantes no tagarelar social requintado. Mulher, jogando cintura, diante das coações e preconceitos. Mulher, contudo e apesar, a um passo do tesouro: o cartucho de papel (GUIMARÃES, 2018, p. 81).

A personagem é, nesta etapa do relato, autoconfiante e demonstra uma enorme garra para ultrapassar as dificuldades, vencendo o preconceito da sociedade, na busca de definir a sua identidade. Conforme Munanga "A construção dessa imagem positiva é importante para todos nós, negros e brancos, pois poderá nos ajudar a compreender, aceitar, reconhecer e respeitar as diferenças" (MUNANGA, 2006, p.134)

É destacado no texto aspectos sob a presença das marcas de uma sociedade patriarcal, na qual os brancos eram tidos como superiores. No capítulo que trata sobre a colação de grau da personagem, presenciamos a organização e empenho da família para se vestir convenientemente, seguindo os padrões de etiqueta determinado pela a sociedade:

[...] concordamos no seguinte: só compraríamos tudo novo para mim. Os outros só compraríamos aquilo que não tivessem mesmo, de jeito nenhum. Portanto, compramos roupa para um, sapato para outro e assim por diante (GUIMARÃES, 2018, p. 82).

Outro fragmento que aparece no decorrer da narrativa é o que evidencia a preocupação do pai em não expor a filha em situações de humilhações, preocupado com o que os amigos de sua filha pensariam dela: “[...] Imagine só... Esquecer de usar meias. Já pensou se um dos seus amigos visse? Deus me livre de te envergonhar!” (GUIMARÃES, 2018, p. 85), ressaltando, assim, a submissão do negro ao branco e o seu silenciamento. 
A partir desse excerto, pode-se pensar que, por mais que a autora procure apresentar uma visão mais positiva do negro, não idealiza as personagens, mantendo-se fiel, em alguns momentos, à própria realidade que condiciona e oprime segmentos sociais pelas marcas do passado que elas carregam em sua existência. Assim, traços da história e artefatos da fíç̧ão comungam na construção verossímil das personagens negras em A Cor da Ternura (2018). Essa construção das personagens permite estabelecer os vínculos entre fatos e circunstâncias do passado que condicionam o modo de agir e pensar das personagens num contexto espaçotemporal contemporâneo.

No enredo presenciamos a conquista um emprego pela protagonista, o enfrentamento, agora, dá-se em sala de aula, quando nos primeiros dias, uma de suas alunas (criança) para na porta da sala, tenta resistir em entrar, e começa a chorar falando: “[...] Eu tenho medo de professora preta - disse-me ela, simples e puramente." (GUIMARÃES, 2018, p. 87). A protagonista tem que realizar todo um trabalho, novamente, para resgatar e efetivar a sua aceitação.

Ao longo da narrativa observamos todo o trabalho de autoaceitação que é feito pela autora, pois, vemos a constante luta da protagonista, perpassando pela fase das dúvidas e incertezas, formação de identidade, negação si própria e o preconceito da sociedade. Todas essas fases são imprescindíveis para formação/construção da sua identidade, conforme bem define Hall (2011, p. 108):

[...] que as identidades nunca são unificadas; que são, na modernidade tardia, cada vez mais fragmentadas e fraturadas; que elas nunca são singulares, mas multiplamente construídas ao longo de discursos, práticas e posições que se cruzam e até podem ser antagônicas. As identidades estão sujeitas a uma historicidade radical, constantemente em processo de mudança e transformação.

Podemos afirmar, também, que Geni Guimarães apresenta, em A Cor da Ternura (2018), de certa forma poética, um aspecto inovador na elaboração discursiva da personagem negra, que no decorrer da narrativa, vai construindo sua própria identidade, apesar das dificuldades e do preconceito presente na sociedade. Além disso, a obra retrata uma história de auto descoberta para a personagem Geni, à medida que cresce como mulher, se descobre como mulher e negra na sociedade brasileira. Reflete também sobre a importância da mulher afrodescendente na formação da família, buscando suas verdadeiras raízes, isto é, o resgate de sua cultura e etnia, sem se deixar abater pelas dificuldades enfrentadas.

Assim, o gênero memorialístico insere-se no estatuto de textos referenciais que descrevem a trajetória de uma vida, são documentos que "servem", inicialmente, à história. $\mathrm{O}$ que possibilita o seu estudo no conjunto da literatura ficcional é a força da linguagem de 
alguns textos e sua capacidade de se imporem como discurso esteticamente elaborado. Sustentados na recriação, na transformação da rememoração em linguagem é que surge a “oportunidade poética". O relato memorialístico só ultrapassa o caráter histórico para se ver enquanto ficção pela produção da linguagem. As memórias literárias se aproximam dos textos históricos quando narram a realidade vivida; por outro lado, aproximam-se do romance porque resultam de um trabalho literário.

A obra Definir Autobiografia de Lejeune (2003) tem sido utilizada como base para diversos trabalhos contemporâneos sobre a autobiografia. Nela, o autor aborda os mecanismos que amparam as narrativas fundadas no eu, como a autobiografia que, para ele, é considerada primeiro como um texto literário. Em síntese, Lejeune, define que autobiografia é "narrativa retrospectiva em prosa que uma pessoa real faz de sua própria existência, quando focaliza sua história individual, em particular a história de sua personalidade" (LEJEUNE, 2008, p. 14), e nesta narrativa deve haver "relação de identidade entre o autor, o narrador e o personagem" (LEJEUNE, 2008, p.15).

No relato memorialístico resgatamos fatos da própria vida e a capacidade que as lembranças têm de se mostrarem como presente, de reviverem a emoção. Construímos o relato pela invocação do vivido, pela recomposição dos guardados na memória do homem, por meio de testemunho de outras pessoas. Podemos constatar tal fato na obra A Cor da Ternura (2018), pois a coincidência entre o nome da personagem e o nome da autora, constitui a identidade do narrador na autobiografia, cuja verdade histórica do que é expresso por sua voz, tanto no relato autobiográfico como nos demais textos fundados na experiência pessoal do autor, é dada por um pacto realizado entre autor e leitor.

Assim,

[...] como já se viu, a importância do contrato, que determina, de fato, a atitude do leitor: se a identidade não for afirmada (caso da ficção), o leitor procurará estabelecer as semelhanças, apesar do autor; se for afirmada (caso da autobiografia) terá a tendência de procurar as diferenças (erros, deformações, etc.). Diante de uma narrativa de natureza autobiográfica, o leitor frequentemente pergunta-se pelo limite, ou seja, procura as rupturas do contrato (independentemente do contrato) (LEJEUNE, 2003, p. 26).

O pacto autobiográfico é um pacto de referencialidade histórica e respeito ao leitor, um compromisso pessoal daquele que conta, pois

[...] o que define a autobiografia para quem a lê, é, sobretudo, um contrato de identidade cujo selo é o nome próprio. O que é verdadeiro também para quem escreve o texto. Se eu escrevo a história da minha vida sem dizer o meu nome, como 
o meu leitor saberá que sou eu? É impossível que a vocação autobiográfica e a paixão do anonimato coexistem no mesmo ser (LEJEUNE, 2003, p. 33).

O olhar do leitor é o que definirá em grande parte o gênero memorialístico. A esse respeito, Lejeune na obra Pacto Autobiográfico, afirma que:

\begin{abstract}
A história da autobiografia seria então, antes de tudo, a história de seu modo de leitura: história comparativa na qual poderíamos fazer dialogar os contratos de leitura propostos pelos diferentes tipos de textos (pois nada adiantaria estudar a autobiografia isoladamente, já que, assim como os signos, os contratos só têm sentido por seus jogos de oposição), e os diferentes tipos de leitura a que esses textos são realmente submetidos. Se podemos dizer que a autobiografia se define por algo que é exterior ao texto, não se trata de buscar, aquém, uma inverificável semelhança com uma pessoa real, mas sim de ir além, pra verificar, no texto crítico, o tipo de leitura que ela engendra, a crença que produz. (LEJEUNE, 2008, p.47)
\end{abstract}

Lejeune (2003) inclui, em sua obra Definir Autobiografia, considerações que também abrangem outros aspectos da questão da autobiografia: as relações entre história e memória, observando que memória e autobiografia tiveram igualmente um estatuto exterior à literatura, antes de se integrarem a ela. Os estudos críticos sobre o gênero contribuem para a sua mudança de estatuto e a sua 'promoção' (LEJEUNE, 2003, p. 312).

A produção da narrativa autobiográfica, assim como a da história, têm como interesse um fator determinante no tempo presente, por algo que está ligado ao momento da produção, porque

[...] a história não se escreve de um lugar intemporal, mas num presente, e é quando ela o esquece que o presente manifesta-se mais. Com algum recuo, o texto histórico assim produzido passa a ser ele mesmo um documento datado, que reflete o esforço de uma época para estruturar o seu universo (LEJEUNE, 2003, p. 312).

Nesse sentido, a narrativa de memórias incorpora o homem em todas as suas dimensões e, ainda como manifestação de linguagem, incorpora também a ambiguidade, própria do homem, própria da linguagem humana. A produção das memórias exige do sujeito autor um tempo de maturação e compreensão das próprias experiências, distanciamento histórico para elaboração e sistematização de uma linguagem articulada ao estatuto do gênero, que possibilite transformar essa experiência em conhecimento. A memória literária é imprescindível na busca da identidade.

\title{
Considerações finais
}

Cientes da extrema importância da leitura para a formação de uma sociedade reflexiva e crítica - e também de que a fase mais importante para o desenvolvimento do gosto em ler é a 
infância -, podemos afirmar que a literatura infantojuvenil precisa ser mais valorizada e deve ser propiciada à criança desde a mais tenra idade. Esta literatura deve ser ofertada não mais apenas como textos pedagógicos, fragmentados e moralizantes, mas também estéticos e com as qualidades literárias que toda a boa literatura exige.

Dessa forma, acreditamos que quando se trata da literatura afro-brasileira, que possui uma história bem mais recente, isso é ainda mais árduo de se obter, até porque, inicialmente, as personagens negras quase não apareciam nas obras literárias e, quando se faziam presentes, eram apresentadas de forma secundária ou pejorativa e nunca como protagonistas.

Justamente por este motivo, há uma necessidade maior ainda, em relação a essa literatura, de dar-lhe o devido valor e reconhecimento no meio literário, devendo receber mais atenção por parte de estudiosos da área, pois o Brasil, apesar de se apresentar como um país de todas as cores e livre de preconceitos, ainda é um lugar onde a discriminação racial impera de forma disfarçada e dissimulada.

A ação da memória na narrativa ou a transformação da memória, individual ou coletiva, em narrativa é um estudo que ainda merece muita atenção. São diversos os trabalhos contemporâneos que procuram estabelecer como se dá esse processo, segundo a consideração que cada um adota sobre a memória e sua relação com as ações do indivíduo. Por isso, nosso estudo buscou compreender como os fatores culturais e sociais podem influenciar em tal processo através da escrita memorialística de Geni Guimarães. Isso nos possibilitou compreender como a personagem negra Geni, de A Cor da Ternura (2018), na literatura infantojuvenil constrói sua identidade no decorrer de sua trajetória de vida, num contexto em que a protagonista da obra ora apresenta atitudes de submissão a uma sociedade dita como superior, neste caso, a branca, e ora apresenta características positivas de aceitação e orgulho de sua cor e pertencimento: a negra.

A obra de Geni Guimarães nos apresenta, através de sua protagonista, o exemplo de que as pessoas negras podem e, principalmente, devem vencer barreiras, e que, apesar das dúvidas e incertezas durante todo o processo de formação da identidade, superam o preconceito e o racismo presentes na sociedade. A identidade não se constrói em um único momento, pois ela passa por fases, que vão desde a separação da criança da mãe, e que percorrem toda a vida do ser humano, ou seja, a identidade não é única, ela é fragmentada, e está sempre em construção, conforme afirma Hall "algo formado, ao longo do tempo, através de processos inconscientes, e não algo inato, existente na consciência no momento do nascimento" (HALL, 2003, p. 38). 
Assim, podemos afirmar que a forma positiva com que as personagens são apresentadas na obra A Cor da Ternura (2018) contribui para que a identidade afrodescendente seja vista sob uma nova ótica, de forma positiva, valorizando a cultura negra e respeitando as raízes ancestrais e através dela pensar nas formas de representação da mulher negra do discurso literário. As problemáticas retratadas ao longo da vida da menina Geni refletem, poeticamente, a desconstrução de discursos hegemônicos acerca da mulher negra, como questões, no que se refere à identidade e à memória.

\section{Referências}

ARBOLEYA, V. J. Questões de literatura infantil e afrodescendência: o poder de ação do personagem negro nas áreas de decisão da narrativa. Revista África e Africanidades. Ano I, n. 4, fev. 2009.

GOMES, N. L. Educação e identidade negra. In: BRITO, Angela Maria B. et al (Orgs). Kulé Kulé: educação e identidade negra. Maceió: EDUFAL, 2004.

GUIMARÃES, G. A cor da ternura. 2. ed. São Paulo: FTD, 2018.

HALL, S. A identidade cultural na pós-modernidade. Tradução de Tomaz Tadeu da Silva e Guacira Lopes Louro. 11. ed. Rio de Janeiro: DP\&A, 2011.

LEJEUNE, P. Definir autobiografia. In MOURÃO, Paula (org). Autobiografia. Autorepresentação. Lisboa: Edições Colibri, 2003

LEJEUNE, P.O pacto autobiográfico: de Rousseau à Internet. Belo Horizonte: Editora UFMG, 2008.

MAGNANI, M. R. M. Leitura, literatura e escola. 2 ed. São Paulo: Martins Fontes, 2001.

MUNANGA, K; GOMES, N. L. O negro do Brasil de hoje. São Paulo: Global, 2006.

POLLAK, Memória e identidade social: estudos históricos. Rio de Janeiro, vol. 5, n. 10, 1992.

SILVA, T. T. A produção social da identidade e da diferença. In: Identidade $e$ diferença: a perspectiva dos estudos culturais. Rio de Janeiro: Vozes, 2009. p. 73-102.

WOODWARD, K. Identidade e diferença: uma introdução teórica e conceitual. In: SILVA, T. T. da. Identidade e diferença: a perspectiva dos estudos culturais. Rio de Janeiro: Vozes, 2009. p. 7 - 72.

YUNES, E. Dados para uma história da leitura e da escrita. In: , Eliane (Org.). Pensar a leitura: a complexidade. Rio de Janeiro: PUC-Rio; São Paulo: Loyola, 2002, p.52-59. 
ZOLIN, L. O. Crítica feminista e Literatura de autoria feminina. In: BONNICI, T; ZOLIN, L. O. (orgs.). Teoria literária: abordagens históricas e tendências contemporâneas. Maringá: Eduem, 2003.

Recebido em 30 de janeiro de 2020. Aceito em 27 de abril de 2020. 